\title{
A Rare Genetic Disorder Dyskeratosis Congenita with Vivid Manifestations
}

\author{
Authors \\ Dr Ghanshyam Verma ${ }^{1}$, Dr Santwana Verma ${ }^{2}$, Dr Nidhi Jindal ${ }^{3}$, Dr GR Tegta ${ }^{4}$ \\ Dr Ajeet $\mathrm{Negi}^{5}$
}

${ }^{1}$ Associate Professor, ${ }^{2}$ Associate Professor, ${ }^{3}$ Ex Resident, ${ }^{4}$ Senior Resident, ${ }^{3}$ Professor and Head Dept of Dermatology, Venereology and Leprosy and Department of Microbiology ${ }^{2}$,

Indira Gandhi Medical College, Shimla, Himachal Pradesh

Corresponding Author

\section{Dr Ghanshyam Verma}

Dept. of Dermatology, Venereology and Leprosy, Indira Gandhi Medical College, Shimla, HP

Email: drshyamverma77@gmail.com

\begin{abstract}
Dyskeratosis congenita $(D C)$ is a rare disease with an estimated annual incidence of, $<1$ in 1 million, with multiple and variable clinical manifestations. It is also known as Zinsser-Engman-Cole syndrome, have progressive bone marrow failure syndrome characterized by the triad of reticulated skin hyperpigmentation, nail dystrophy, and oral leukoplakia. Telomerase dysfunction, ribosome deficiency, and protein synthesis dysfunction evidence exists in this disorder. Early mortality is often associated with bone marrow failure, infections, fatal pulmonary complications, or malignancy. We report two cases of DC one with left hip avascular necrosis and other with fatal pulmonary complications, multidrug resistant pulmonary tuberculosis. First patient had onset of symptoms at 10 years of age with lacy reticulated pigmentation over face, neck, upper chest, forearms and hands, nail dystrophy, intraoral lichenoid pigmentation and rough, sparse greyish hair and painful left hip joint. Episodes of severe anaemia managed with blood transfusions. No features suggestive of GIT, pulmonary and neurological involvement and no evidence of any malignancy were seen in first case. Avascular necrosis of hip joint is a still rare association with DC. He was managed with supportive treatment and left hip replacement surgery. Second case had skin and mucosal manifestations with total teeth loss by the age of 26 years, sensory neural deafness in left ear, drug resistance pulmonary tubercular infection as bone marrow failure resulted in immunosuppressive state in this case. Ultimately the patient scum to pulmonary manifestations of DC in the form of opportunistic infection.
\end{abstract}

Keywords: avascular hip necrosis, dyskeratosis congenital, reticular pigmentation, bone morrow failure, drug resistant pulmonary tuberculosis.

\section{INTRODUCTION}

Dyskeratosis congenita (DC) is a rare, hereditary disease, which was first described by Zinsser in 1906. (1) Dyskeratosis is Latin and means the irreversible degeneration of skin tissue, and congenita means inborn. It is an inherited bone marrow failure (BMF) and cancer predisposition syndrome caused by defects in telomere biology. The consequences of DC affect all body systems; these may include the diagnostic triad of abnormal 
nails, reticular skin pigmentation, and oral leukoplakia. BMF, pulmonary fibrosis, liver disease, neurologic and ophthalmic abnormalities and increased risk for cancer also occur. ${ }^{(2,3)}$ The known clinical complications are listed in Table $1 .^{(2,4)}$

\begin{tabular}{|c|c|}
\hline & Clinical features in DC \\
\hline Systems & Findings \\
\hline Dermatologic & $\begin{array}{l}\text { Lacy, reticular hyper pigmentation, } \\
\text { primarily of the neck and chest; subtle } \\
\text { or diffuse hyper- or hypo pigmentation, } \\
\text { Abnormal finger and toe nails, Early } \\
\text { gray hair or hair loss and hyperhidrosis. }\end{array}$ \\
\hline $\begin{array}{ll}\text { Growth } & \text { and } \\
\text { Development } & \end{array}$ & $\begin{array}{l}\text { Short stature, Intrauterine growth } \\
\text { retardation, Developmental delay. }\end{array}$ \\
\hline Ophthalmic & $\begin{array}{l}\text { Epiphora, Blepharitis, Sparse eyelashes, } \\
\text { ectropion, entropion, trichiasis, } \\
\text { Exudative retinopathy. }\end{array}$ \\
\hline Dental & $\begin{array}{l}\text { Caries, periodontal disease, decreased } \\
\text { root/crown ratio, Taurodontism } \\
\text { (enlarged pulp chambers of the teeth). }\end{array}$ \\
\hline $\begin{array}{l}\text { Ears, Nose and } \\
\text { Throat }\end{array}$ & $\begin{array}{l}\text { Oral leukoplakia, lichen planus like oral } \\
\text { pigmentation, Deafness (rare), head and } \\
\text { neck cancer. }\end{array}$ \\
\hline Cardiovascular & $\begin{array}{l}\text { Atrial or ventricular septal defects, } \\
\text { fibrosis, dilatated cardiomyopathy. }\end{array}$ \\
\hline Respiratory & Pulmonary fibrosis. \\
\hline Gastrointestinal & $\begin{array}{l}\text { Esophageal stenosis, Enteropathy, Liver } \\
\text { fibrosis }\end{array}$ \\
\hline Genitourinary & $\begin{array}{l}\text { Urethral stenosis in males, Epithelial } \\
\text { cancers }\end{array}$ \\
\hline Musculoskeletal & $\begin{array}{l}\text { Osteoporosis, Avascular necrosis of the } \\
\text { hips and shoulders }\end{array}$ \\
\hline Neurologic & $\begin{array}{l}\text { Developmental delay, Microcephaly, } \\
\text { Cerebellar hypoplasia Intracranial } \\
\text { calcifications . }\end{array}$ \\
\hline Psychiatric & Schizophrenia \\
\hline Endocrine & Hypogonadism \\
\hline Hematologic & $\begin{array}{l}\text { Bone Marrow Failure a common } \\
\text { presenting sign, Myelodysplastic } \\
\text { Syvdrome, Leukemia. }\end{array}$ \\
\hline Immunologic & Immunodeficiency \\
\hline
\end{tabular}

\section{CASE REPORT}

A 25 year old male presented to the department of dermatology with lacy reticulated pigmentation for last 15 years distributed over face, neck, upper chest, forearms and hands. There was associated nail dystrophy for the last 13 years, intraoral pigmentation and avascular necrosis of the left hip though the patient was not on any systemic steroid therapy for the last 10 years. He also had rough and sparse hair along with premature canitis. There was past history of suffering from a single episode of severe anaemia at 10 years of age for which three blood transfusions were given (Table 2). There was no history of associated hyperhidrosis, deafness, epiphora, respiratory complaints, developmental delay or neurological and psychiatric symptoms. He had three sibling two sisters and one brother all were normal, also there was no history of similar complaints in first or second cousins.

Table 2. Sequelae of events in the development of disease.

\begin{tabular}{|c|c|c|}
\hline AGE & $\begin{array}{c}\text { SIGNS \& } \\
\text { SYMPTOMS }\end{array}$ & TREATMENT \\
\hline 10 years & Severe anaemia & Blood transfusions \\
\hline 10 years & $\begin{array}{c}\text { Hyper and } \\
\text { hypopigmented } \\
\text { areas all over the } \\
\text { body. }\end{array}$ & $\begin{array}{l}\text { Vitamin supplements, } \\
\text { topical cream }\end{array}$ \\
\hline 12years & $\begin{array}{l}\text { Nail atrophy of } \\
\text { toes,diffuse skin } \\
\text { pigmentation }\end{array}$ & Supportive treatment \\
\hline 15 years & $\begin{array}{l}\text { Pain left hip joint } \\
\text { radiating to knee } \\
\text { joint }\end{array}$ & $\begin{array}{c}\text { Hip replacement } \\
\text { surgery but postponed } \\
\text { due to severe anemia. }\end{array}$ \\
\hline
\end{tabular}

CUTANEOUS EXAMINATION: Lacy reticulated pigmentation with interspersed areas of hypopigmented macules distributed over face, neck, upper chest, back, forearms and hands[Figure - 1.1, $1.2 \& 1.3]$. Premature canities and dystrophic finger and toe nails. [Figure1.3\&1.4]. Diffuse lichenoid intraoral pigmentation [Figure1.5]. trichiasis and lid margin pigmentation [Figure 1.6] .

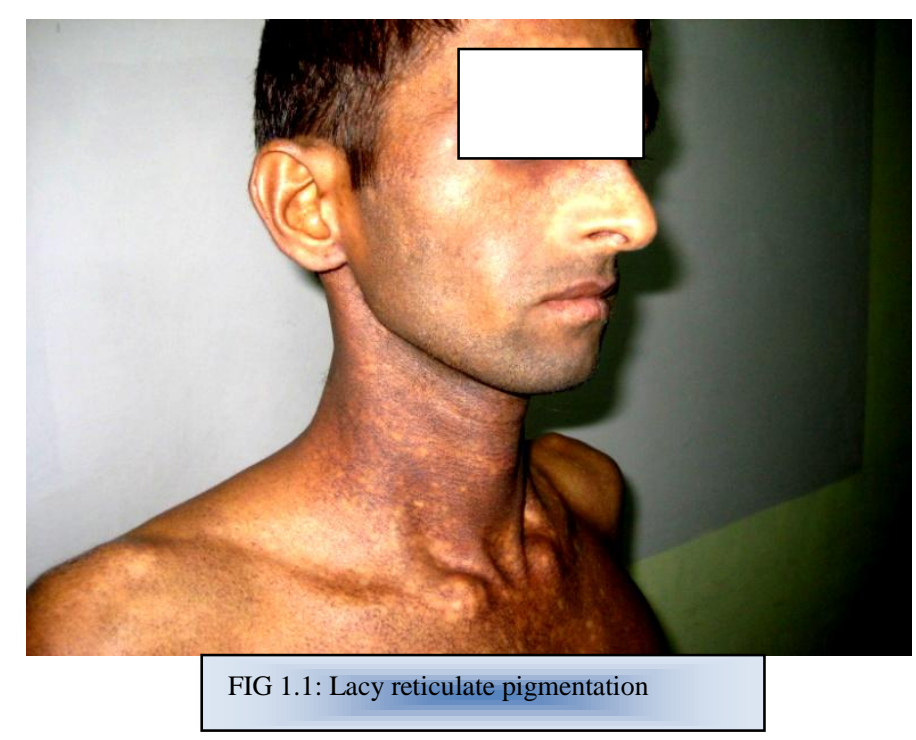




\begin{tabular}{|l|l|}
\hline JMSCR Vol||05||Issue||05||Page 22476-22484||May & 2017 \\
\hline
\end{tabular}
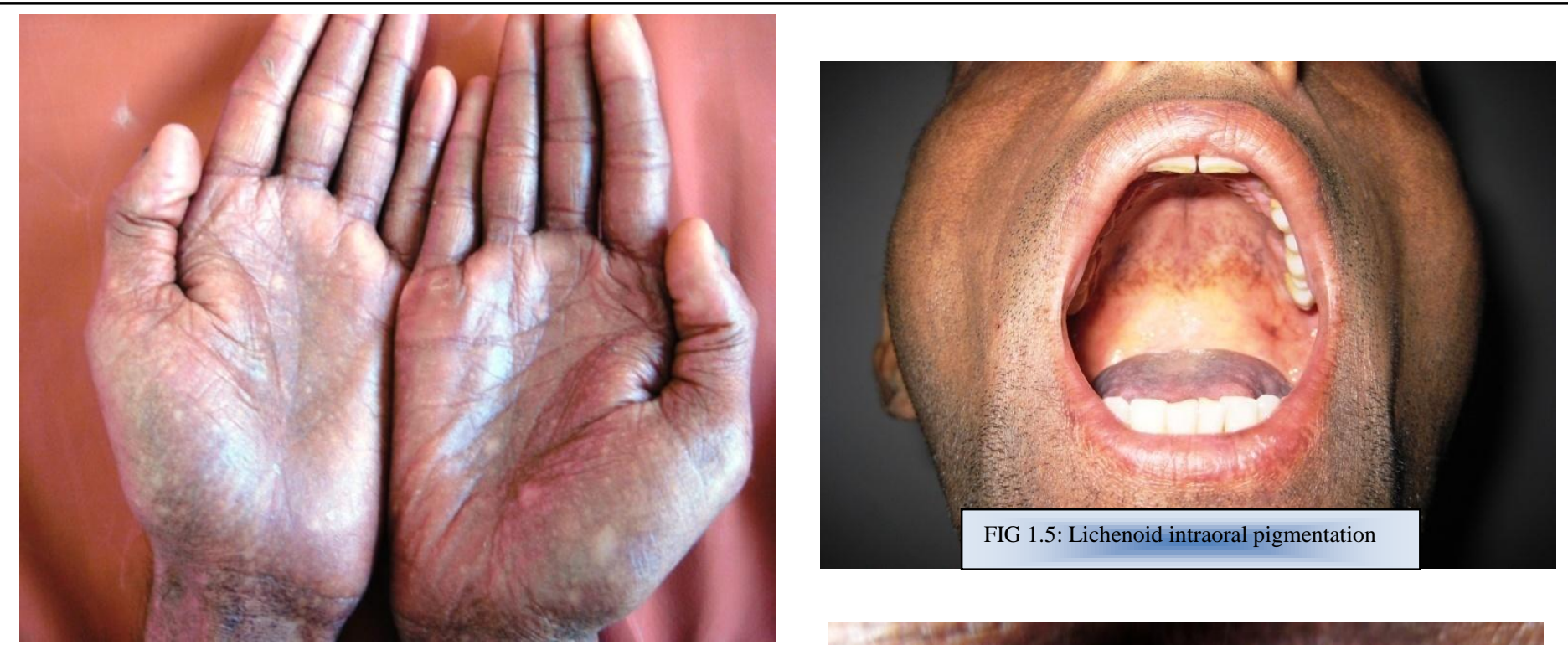

FIG 1.2: Hyperkeratosis of palms.
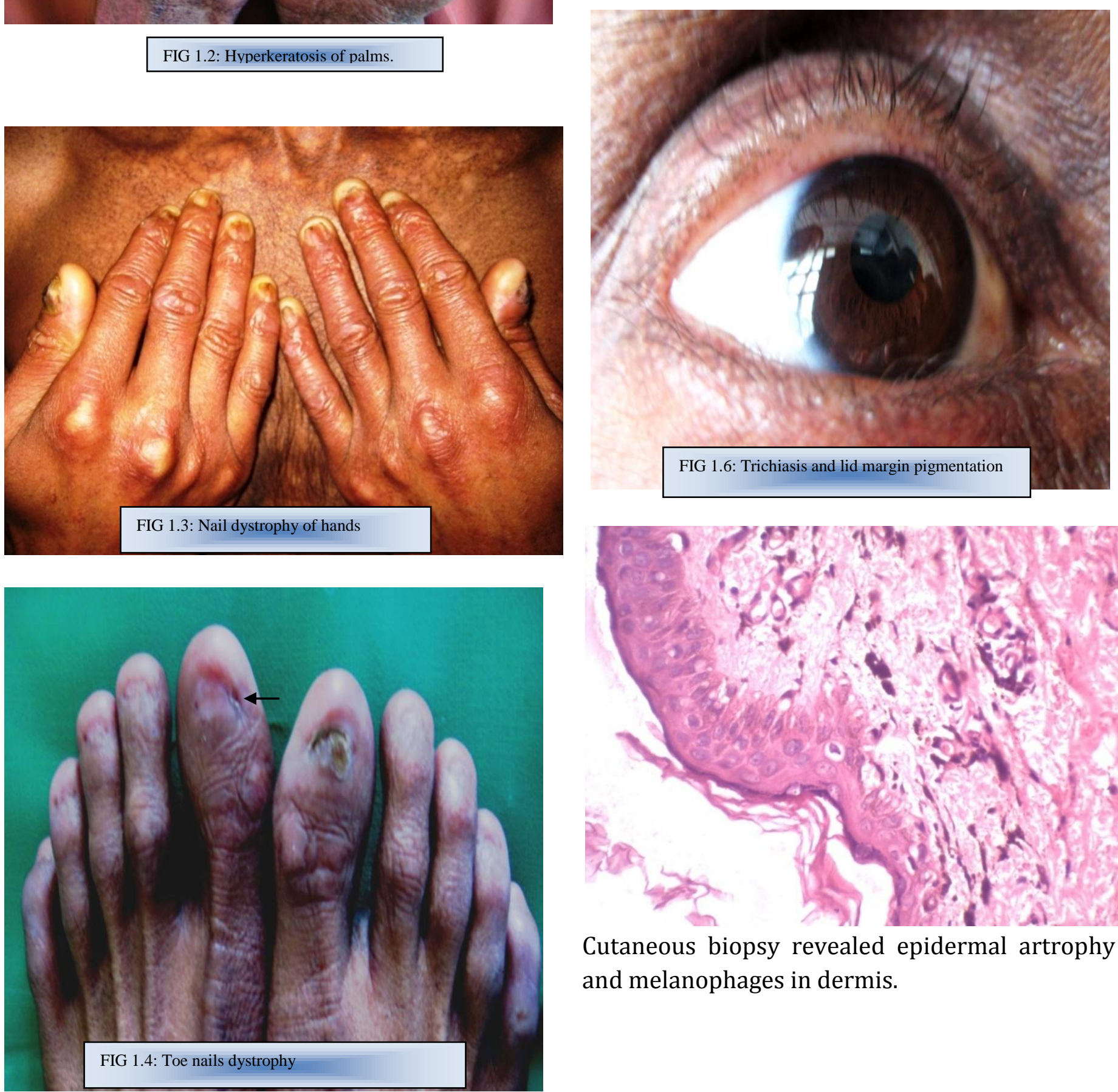

Cutaneous biopsy revealed epidermal artrophy and melanophages in dermis. 


\section{JMSCR Vol||05||Issue||05||Page 22476-22484||May}

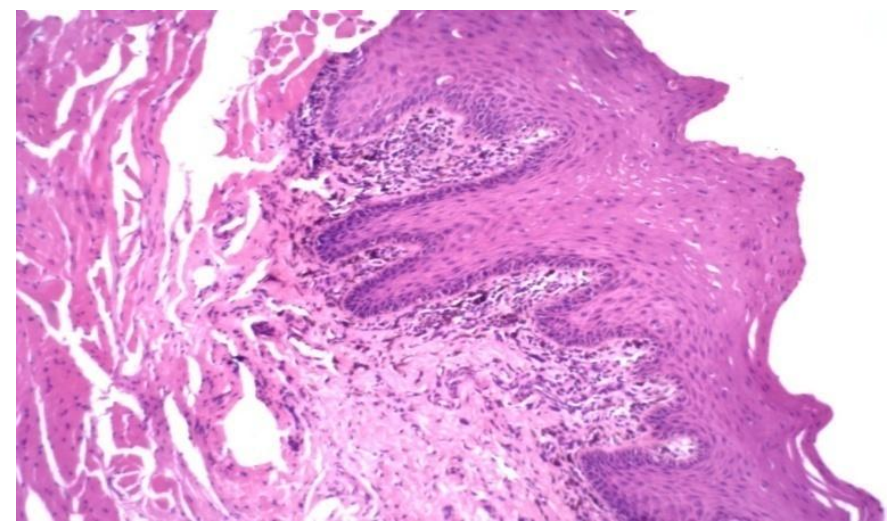

Mucosal biopsy revealed histopathological changes consistant with lichen planus.

INVESTIGATIONS: Routine biochemical investigations were normal. Hemoglobin $(\mathrm{Hb})$ was $8.4 \mathrm{~g} / \mathrm{dL}$, total leucocyte count $12,450 / \mathrm{cmm}$ with a differential count of N64,L36,M0 and platelet count of $119,000 / \mu \mathrm{L}$. Peripheral blood smear and bone marrow aspirate examination revealed hypoplastic anemia. Pulmonary Function Test, E.C.G. and Echocargraphy were normal. Skiagram of chest and skull were normal, C.T. head was normal. USG abdomen, kidney and urinary bladder revealed no abnormality. Eye examination revealed bilateral lid margin pigmentation and trichiasis, slit lamp and fundus examination was normal. Ear, nose and throat examination was within normal limits. Genetic mutational analysis could not be done because of non affordability of the patient.

MRI of left hip joint: confirmed avascular necrosis.

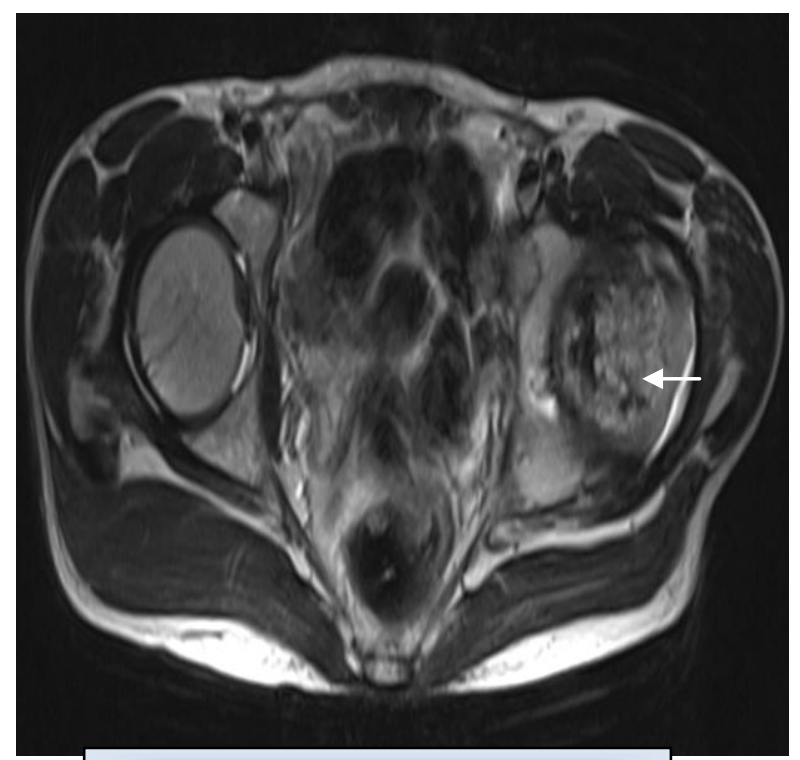

FIG 1.7: Transverse $\mathrm{T}_{2} \mathrm{~W}$ image of hip joints
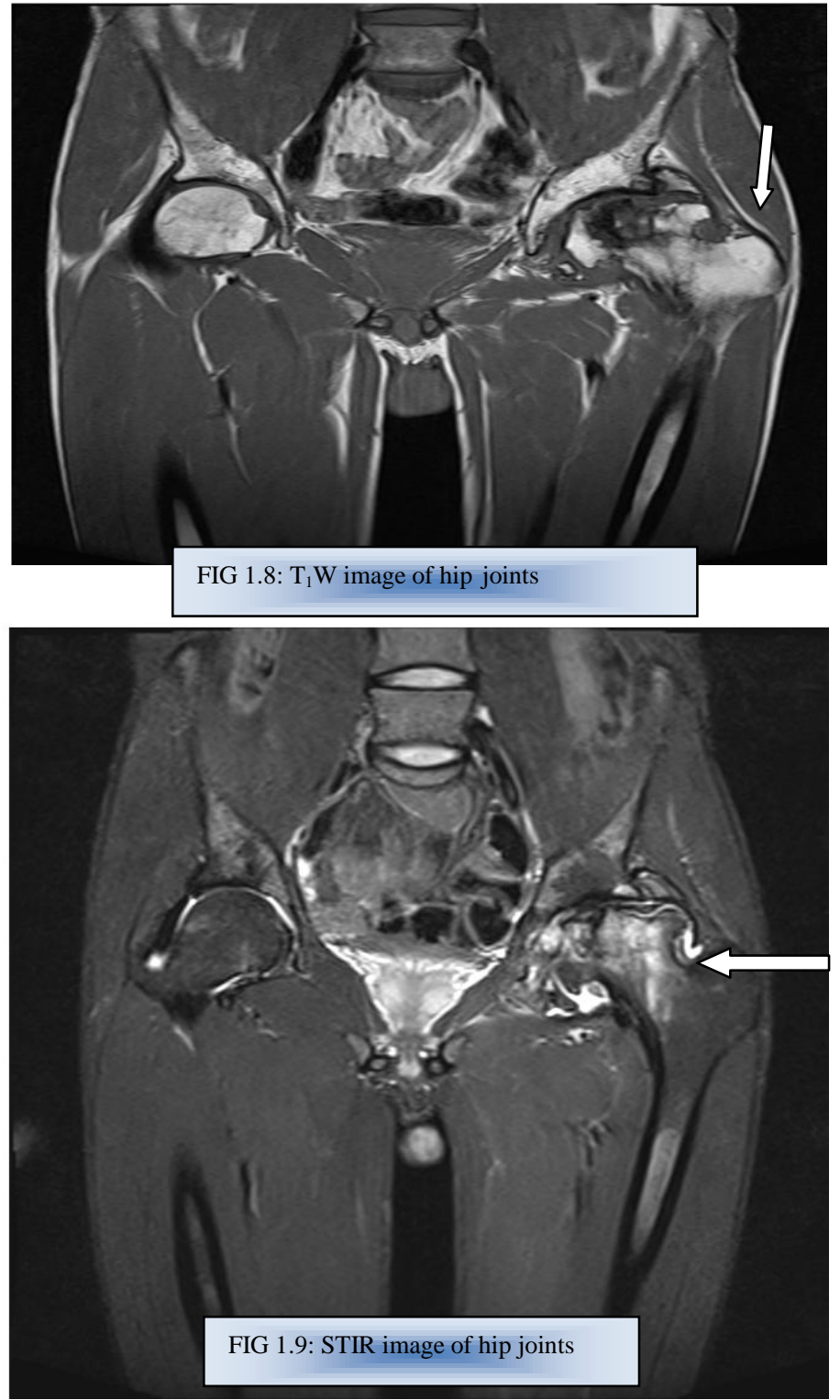

MANAGEMENT: Supportive therapy.

Orthopaedic treatment, hip replacement surgery was done.

\section{Case 2}

A 47 years male presented to the department of pulmonary medicine with a diagnosis of Koch's chest, with asymptomatic skin lesions, since early childhood as brownish discolouration with interspersed whitish lesions over nape of neck which progressively spread to involve the trunk and lower limbs. At the age of 26 years he lost all his teeth with in a period of 2 years. He noticed asymptomatic pigmentation over tongue and buccal mucosa. For few years he developed hearing loss in 


\section{JMSCR Vol||05||Issue||05||Page 22476-22484||May}

left ear and dystrophy in toe nails in childhood. He had history of cough and sputum for last 20 years with severe dyspnoea from last 2 years. No urinary and bowel complaints, No complaints of vomiting, diarrhoea, haemoptysis and melena. He noticed significant weight loss over last 2 years. He was treated for Koch's chest 12 years back. Now his sputum examination by concentration method revealed acid fast bacilli (AFB) and was started on anti tubercular medication.

In family no similar illness in the sibling, but one of his two sons, who is 6 years old had oral pigmentation, mongolian spots and nail dystrophy with anaemia and one 13 year old daughter has only nail dystrophy.

On general physical examination he had thin built with poor nutrition, pale, emaciated look, pedal oedema, with cervical and axiallary lymphadenopathy.

\section{MUCO-CUTANEOUS EXAMINATION}

Over neck, chest, trunk, and extensors of the extremities revealed reticulate brownish hyperpigmentation interspersed hypopigmentation. Oral and tongue mucosa showed lichenoid reticulated pigmentation. All the teeth were lost. Nail dystrophy in left foot toe nails and mild changes in finger nails.

On investigations Complete haemogram:- $\mathrm{Hb}$ $7.1 \mathrm{gm} \%$, TLC $5.65 \mathrm{~m} / \mathrm{mm} 3$, platelets $1.5 \mathrm{~m} / \mathrm{mm} 3$ ESR $110 \mathrm{~mm} / 1^{\text {st }} \mathrm{hr}$ with peripheral smear showing picture consistent with diamorphic anemia.

Bone marrow examination:- Revealed diamorphic anemia predominantly megaloblastic with no evidence of malignancy and no parasites or granuloma.

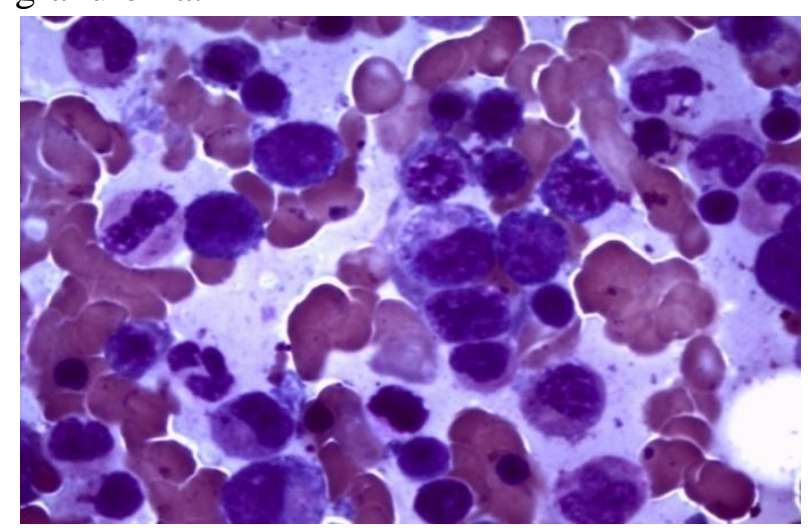

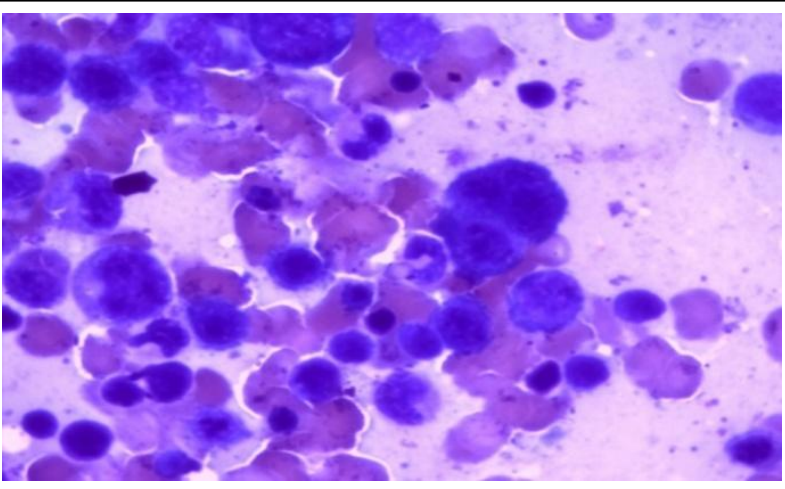

Bone marrow revealed dimorphic Anemia (predominantly megaloblastic picture, no evidence of any granuloma or malignancy) in figure $a$ and $b$.

HIV serology was non reactive. Bio-chemistry was normal, Fasting blood sugar $68 \mathrm{mg} \%$. Skin biopsy revealed keratinising stratified squamous epithelium with focal basal layer vacuolization. Upper dermis reveals numerous scattered melanophages along with mild mononuclear inflammatory cell infiltrate and was consistent with dyskeratosis congenita as shown below in this histomicrophotograph.

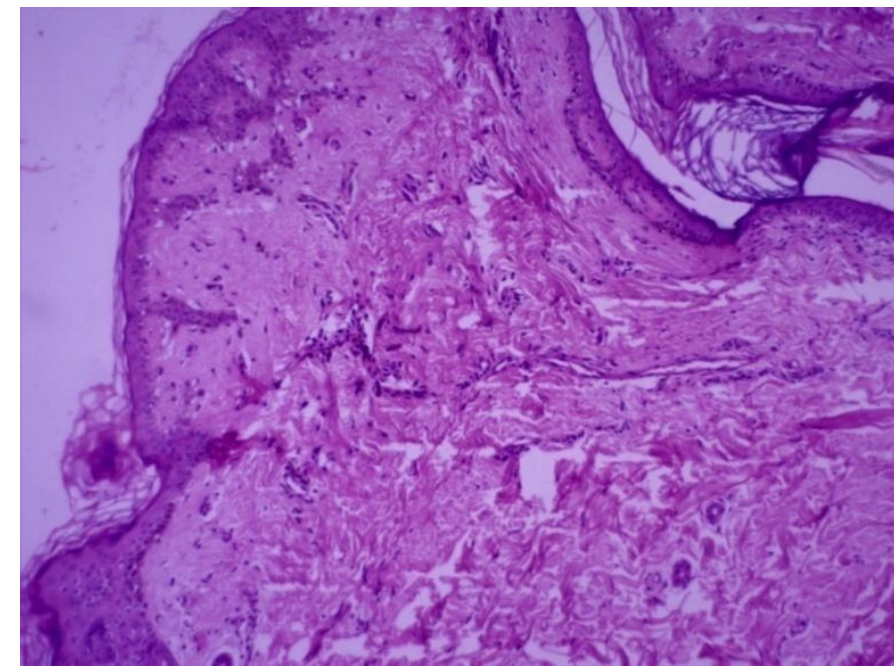

Mucosal biopsy revealed stratified squamous epithelium with acanthosis mild parakeratosis with focal spongiosis. Upper dermis reveals numerous scattered melanophages along with lymphocytic infiltrate as seen in the following microhistophotograph.

Figure a and b 


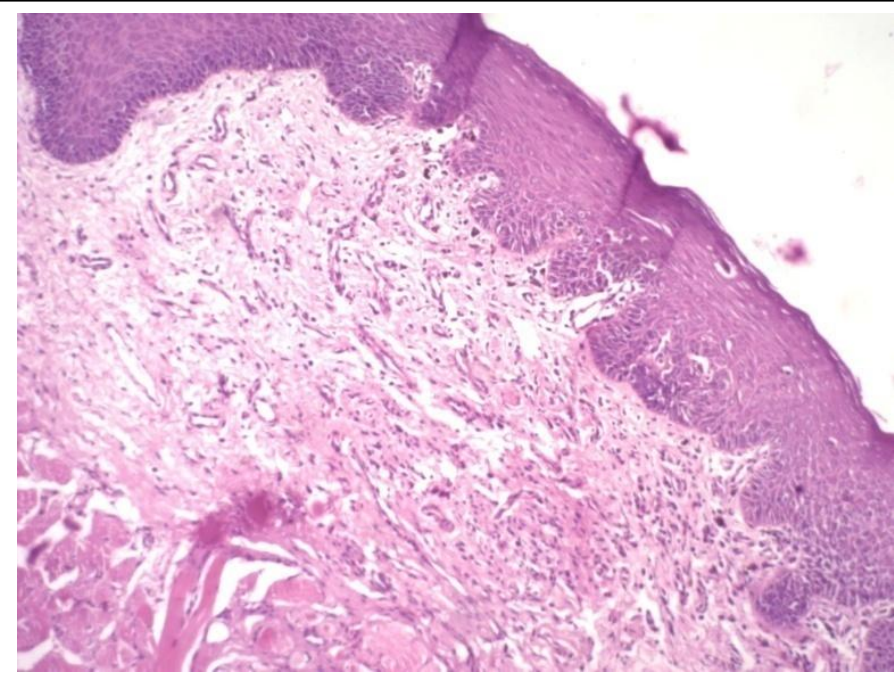

On chest $\mathrm{X}$ ray examination left hemi-thorax shows in-homogenous opacity with plural effusion and pleural thickening, Rt. upper zone shows inhomogenous opacity with fibrotic bands. Eye examination on slit lamp revealed maculopathy. ENT examination showed wax in Rt. ear with sensory neural hearing loss on PTA examination. He was diagnosed a case of multidrug resistant (MDR) pulmonary tuberculosis. After streptomycin injection he developed acute urticaria and angioedema so streptomycin was stopped and maintained on etheonamide $250 \mathrm{mg}$ bd, pyraznamide $1000 \mathrm{mg}$ od, ethambutol $800 \mathrm{mg}$ od, levofloxacin $750 \mathrm{mg}$ od, ciloserine granules 1 tsf tds with lemon juice, and tricox $250 \mathrm{mg}$ bd. Along with iron \& multivitamin supplementation.

Subsequently he developed depressive symptoms and was started on duloxitine 20mgbd and clonazepam $0.5 \mathrm{mg}$ hs. He was again admitted after 4 months with complaints of pain abdomen with ascitis, anasarca, for 2 months, hypothyroidism, malnutrition, hypotension, prolapsed haemrroids and severe anamia .

On investigations Severe anemia--- $\mathrm{Hb}$ 5.5gm, TLC 2.94million/cmm, ESR-80mm,

Peripheral smear revealed ansiocytosis with predominant macrocytes, schistocytes, with moderate hypochromasia and reduced platelets with overall picture of diamorphic anemia.

Blood sugar-80mg\%, proteins 6gm, Alb-2.2gm,Bil.$0.4 \mathrm{mg}$, SGOT/SGPT-27/15,Urea $11 \mathrm{mg} \%$, creatinene- $0.4 \mathrm{mg} \%$, with normal electrolytes.
Urine examination ---albumin traces, no sugar, puscells-10-20/hpf, RBC--15-16/hpf, 24hrs urine-260mg/L proteins. Urine culture---sterile.

Sputum examination became negative for AFB even with conc. method. Plural fluid Proteins1gm\%, ADA --12U/L. Peritoneal fluid--WBC $-160 / \mathrm{cmm}$, Lymphocytes - 25/cmm, PMNC-15/cmm, ADA -16U/L. Ascitic fluid revealed occasional macrophages, degenerated mesothelial cells with neutrophils, and occasional lymphocytes with no malignant cells.

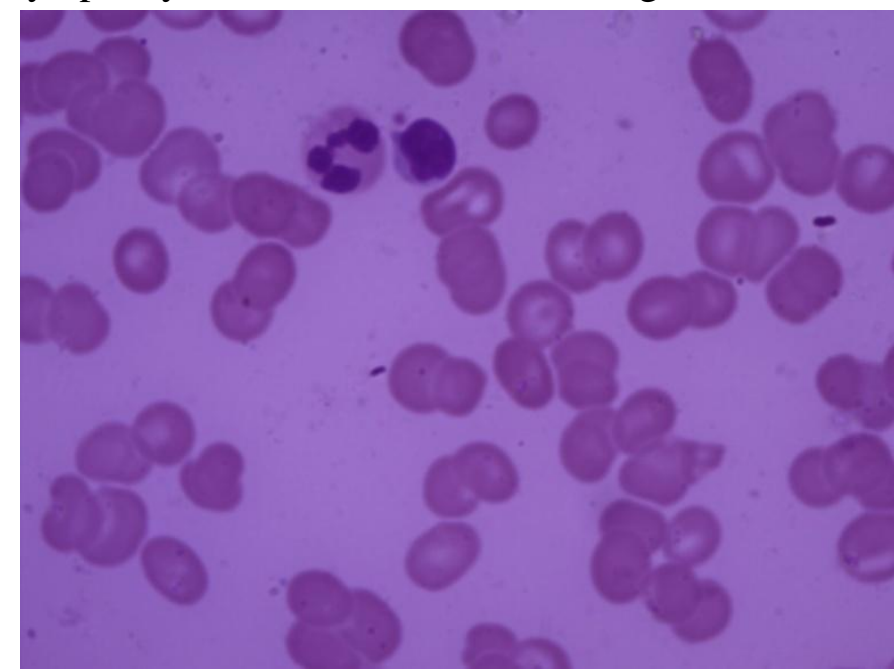

On USG Abdomen shows ascitis with no lymphadenopathy, or mass.

Echocardiography revealed pulmonary arterial hypertension with TR with pericardial effusion with normal LV/RV systolic function. He was managed on mycopas granules 1 tsf with fruit juices modified ATT (pyrizinamide1500mg, ethambutol 800mg and tricox 250mg tds).Thyronine 50ug daily, along with multiple blood transfusions and albumin transfusions with high protein diet. Dopamine drip was started to treat fluctuating BP with vital monitoring, frequent ascetic taps were done. Sclerotherapy was done for prolapsed haemorrhoids (grade2). He developed oral thrush for which started on fluconazole150mg daily. But he scum to the illness and died due to sudden cardiopulmonary arrest. 


\begin{tabular}{|l|l|}
\hline JMSCR Vol||05||Issue||05||Page 22476-22484||May & 2017 \\
\hline
\end{tabular}

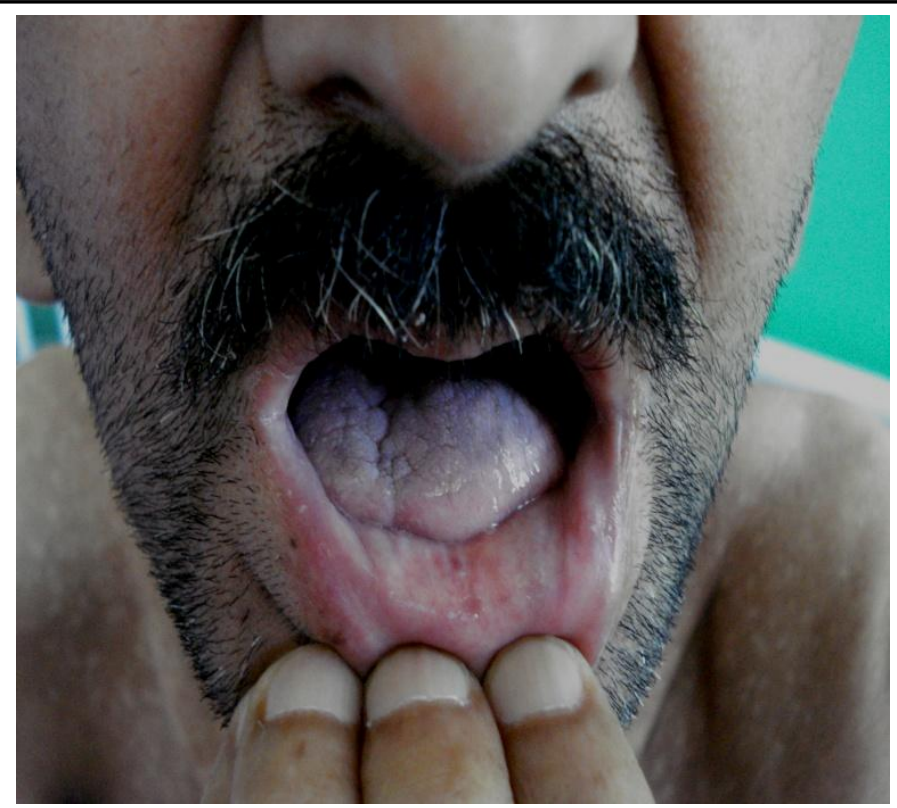

Total teeth loss with lichenoid pigmentation over tongue.

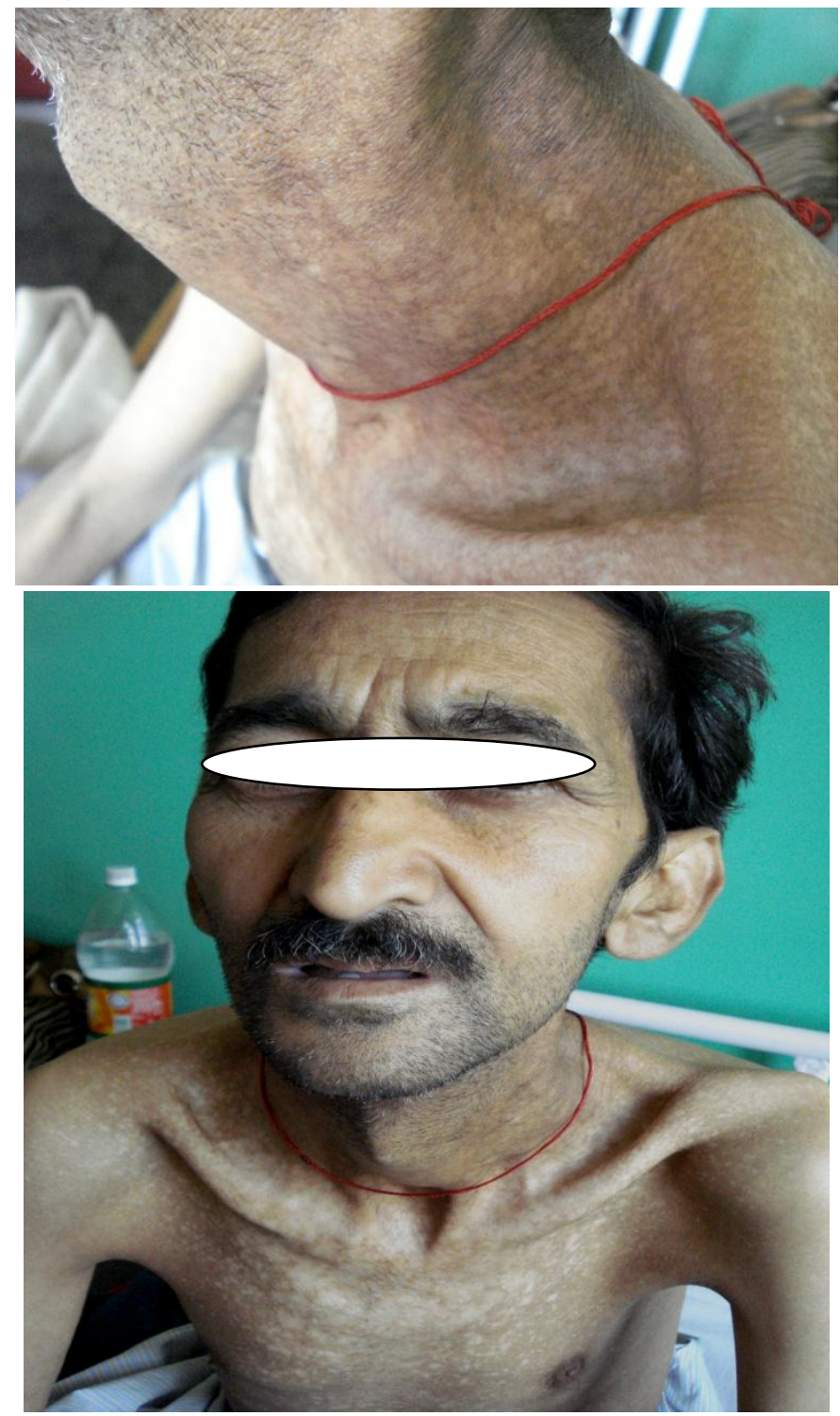

Lacy reticulate pigmentation over face, neck, chest.
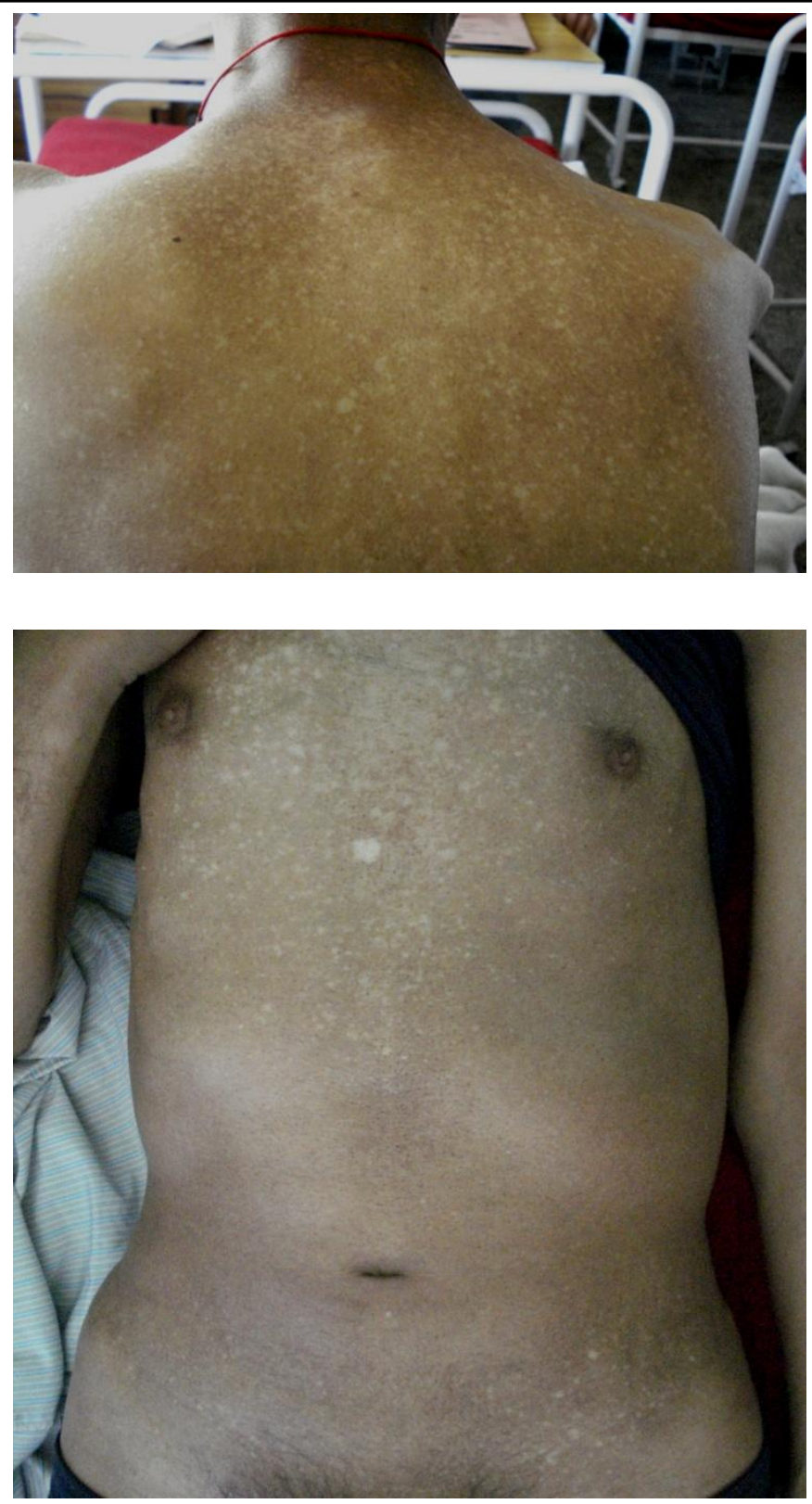

Lacy reticulate pigmentation of back and trunk.

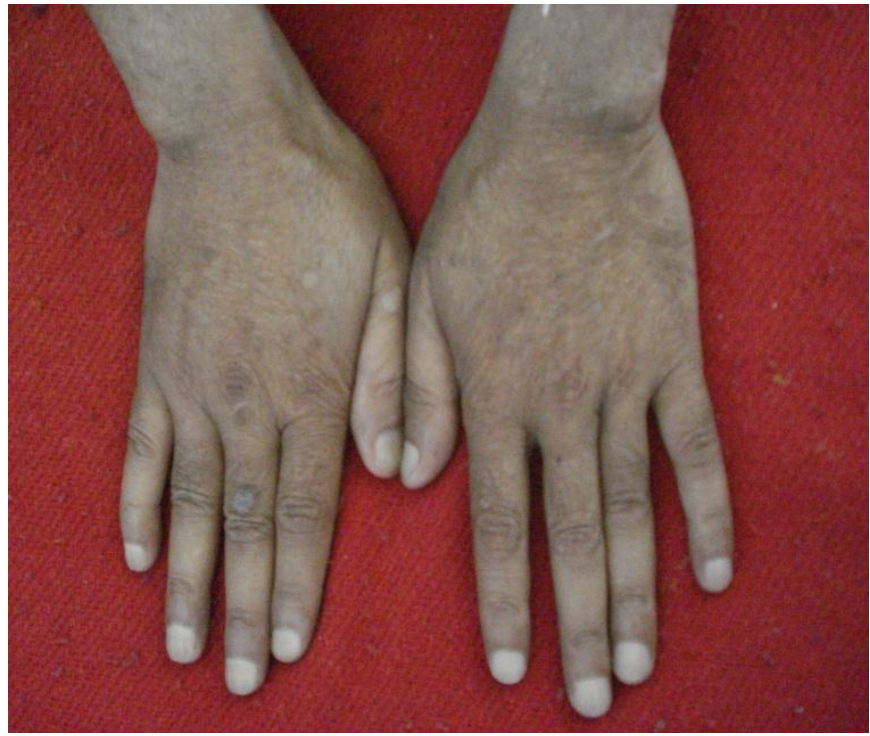

Nail dystrophy and pigmentation of hands 


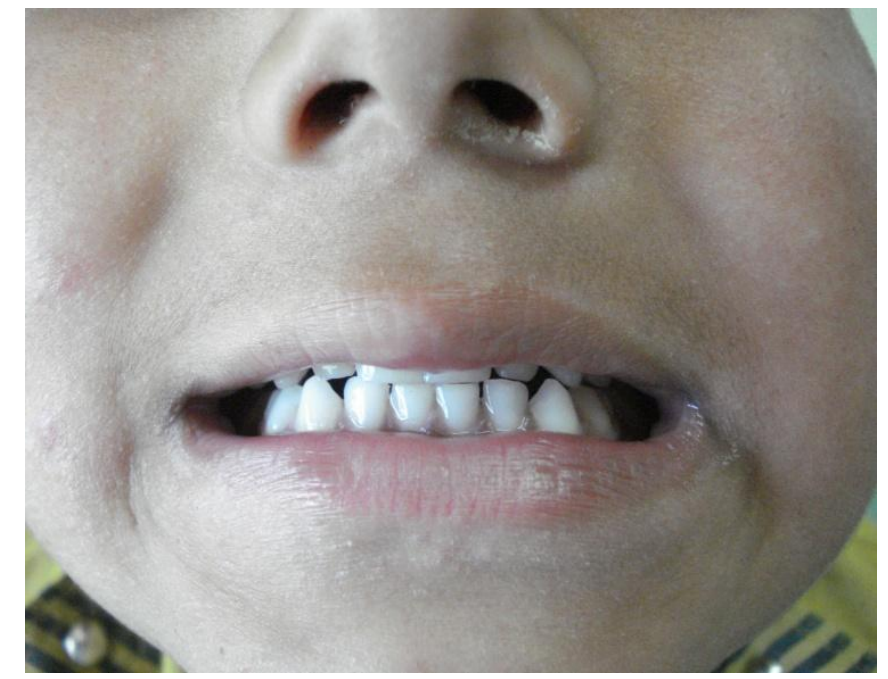

Normal teeth in the child.

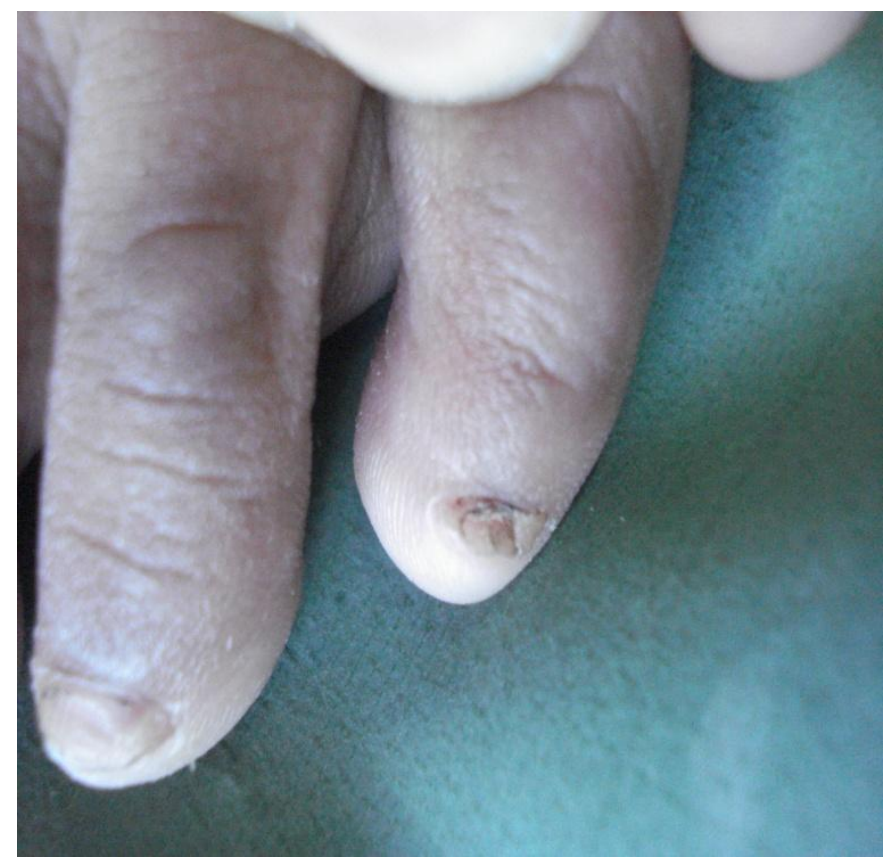

Nail dystrophy in the child

\section{DISCUSSION}

Dyskeratosis congenita (DC) is an inherited disorder of the mucocutaneous and hematopoietic systems in association with somatic abnormalities. DC can be a fatal condition with multisystem manifestations. The clinical diagnosis of classical DC requires at least two features of the triad of dysplastic nails, lacy reticular pigmentation of the upper chest or neck, and oral leukoplakia. ${ }^{(2,4)}$

Skin and nail findings usually become apparent in the 1 st 10 year of life, whereas oral leukoplakia is seen later. ${ }^{(5)}$

The pattern of inheritance may be X-linked (Zinsser-Cole-Engleman syndrome), autosomal dominant (dyskeratosis congenita, Scoggins type) or autosomal recessive. However, in a large proportion of patients dyskeratosis congenita occurs sporadically.

Approximately $85 \%$ of patients are male, compatible with $\mathrm{X}$-linked recessive inheritance. Approximately $15 \%$ of patients appear to have either autosomal dominant or autosomal recessive modes of inheritance. The $\mathrm{X}$-linked recessive form of DC maps to Xq28, and many mutations have been identified in the $\mathrm{DKCl}$ gene, which codes for the nuclear protein dyskerin. Dyskerin may be involved in ribosomal assembly and RNA production. The autosomal dominant form is due to mutations in the TERC gene that encodes the RNA component of telomerase that is responsible for telomere maintenance. Lack of the protein telomerase contributes to the aging process and stem cell death.

In our patient systemic involvement was in the form of bone involvement as his left hip joint showed avascular necrosis without any systemic steroid therapy and episodes of severe anemia (bone marrow failure). Only few reports of hip joint aseptic/avascular necrosis are there in literature. Osteoporosis and the associated risk of fracture are major clinical challenges.

The marrow failure may be due to progressive attrition and depletion of hematopoietic stem cells, which manifests as pancytopenia. Alternatively, marrow dysfunction may represent a failure of replication and/or maturation of stem cells. Constitutional pancytopenia; aplastic anemia occurs in approximately $50 \%$ of cases, usually in the 2 nd decade of life. Patients also have a predisposition to cancer and MDS.

Bronchopulmonary manifestations of DC can be divided into three groups; 1] opportunistic infections such as pneumocystis carinii pneumonia (6), 2] allergic lung diseases like asthma and 3] interstitial pneumonitis. In DC patients, immunological abnormalities such as T-cell immunodeficiency, decreased natural killer cell activity and a deficit of cell-mediated immunity have also been reported. Opportunistic infections are thought to ensue as a result of these 
immunodeficiency and frequently complicated by haematological abnormalities. ${ }^{(7)}$ Our second patient had severe pulmonary involvement in the form of opportunistic infection (MDR pulmonary tuberculosis). Interstitial lung fibrosis is common presentation in patients of DC.

$\mathrm{BMF}$ is the most frequent complication of DC in children, whereas adults suffer from pulmonary fibrosis which may be the cause of mortality. Pulmonary fibrosis, characterized by loss of lung epithelium, prominent fibrosis, and impaired gas exchange and abnormalities of pulmonary vasculature are seen in about $80 \%$ of cases. ${ }^{(8)}$

There is no effective and curative treatment for DC. The most serious aspect of dyskeratosis congenita, bone marrow failure, is treated with Erythropoietin, that stimulates the production of red blood cells, and Neupogen, which stimulates the production of white blood cells. ${ }^{(9)}$ Androgen therapy may improve but not cure aplastic anemia. Colony-stimulating factors used to stimulate bone marrow in patients with cytopenia of one or more cell lineage. Stem cell transplantation is recommended if there is an HLA matched sibling donor. Chemotherapy with bleomycin or cyclophosphamide is effective for treating leukoplakia associated with DC. ${ }^{(1)}$

Vitamin A derivative, etretinate is effective for treating leukoplakia in DC. ${ }^{(10)}$ In future gene therapy can provide an alternative therapy for management of this fatal condition.

\section{CONCLUSION}

This rare disease of vivid manifestations can be easily suspected or diagnosed if asymptomatic cutaneous features are noted early and taken seriously and further the patient should be kept under surveillance to manage the risks of BMF and consequences of systemic involvements, including early onset of malignancy in dyskeratosis congenita. High index of suspicion and multispecialty consultation approach is required for correct diagnosis and management of this rare disease.

\section{REFERENCES}

1. Tanaka A, Kumagai S, Nakagawa K, Yamamoto E. Cole-Engman syndrome associated with leukoplakia of the tongue: a case report. J Oral Maxillofac Surg 1999; 57:1138-41.

2. Drachtman RA, Alter BP. Dyskeratosis congenita: clinical and genetic heterogeneity. Report of a new case and review of the literature. Am J Pediatr Hematol Oncol 1992; 14(4):297304.

3. Walne AJ, Dokal I. Dyskeratosis congenita: a historical perspective. Mech Ageing Dev 2008; 129(1-2):48-59.

4. Dokal I. Dyskeratosis congenita in all its forms. Br J Haematol 2000; 110(4): 768-79.

5. Melvin H. Freedman. Kliegman: Nelson Textbook of Pediatrics, 18th ed. The Pancytopenias ch 468.

6. Wiedemann HP, McGuire J, Dwyer JM, et al. Progressive immune failure in dyskeratosis congenita. Report of an adult in whom pneumocystis carnii and fatal disseminated candidiasis developed. Arch Intern Med 1984; 144: 397

7. Imokawa S, Sato A, Toyoshima M, Yoshitomi A, Tamura R, Suda T, Suganuma H, Yagi $\mathrm{T}$, Iwata $\mathrm{M}$, Hayakawa $\mathrm{H}$, et al. Dyskeratosis congenita showing usual interstitial pneumonia. Intern Med.1994; 33(4):226-30

8. Fernández García MS, Teruya-Feldstein J. The diagnosis and treatment of dyskeratosis congenita: a review. J Blood Med. 2014; 5:15767.

9. Erduran E, Hacisalihoglu S, Ozoran Y. Treatment of dyskeratosis congenita with granulocyte-macrophage colony-stimulating factor and erythropoietin. J Pediatr Hematol Oncol. Apr 2003; 25(4):333-5.

10. Tomita K, Ishii M. A case of Cole- Engman syndrome: Effect of etretinate on the oral leukoplakia. Acta Dermatol Kyoto 1992; 87:567. 